\title{
THE DEVELOPMENT OF A COMPETENCE SCALE FOR LEARNING SCIENCE: INQUIRY AND COMMUNICATION
}

Received: 29 July 2009; Accepted: 27 October 2010

\begin{abstract}
The objective of this study was to develop an instrument to measure school students' competence in learning science as part of a large research project in Taiwan. The instrument consisted of 29 self-report, Likert-type items divided into 2 scales: Competence in Scientific Inquiry and Competence in Communication. The Competence in Scientific Inquiry scale contained 4 subscales: presenting questions and hypothesis, planning, experimenting and data gathering, and data analyzing, interpreting, and concluding. The Competence in Communication scale contained 4 subscales: expressing, evaluating, responding, and negotiating. Students were recruited randomly from primary, junior, and senior high schools in different regions of Taiwan to validate the instrument and establish its reliability and validity. The results of the analyses indicate that the instrument, scales, and subscales have reasonable internal consistency; that the theoretical structure was supported by empirical data; and that the subscales are homogeneous. These results indicate that it is an appropriate tool for measuring students' competence in learning science. Implications and suggestions for further studies are included.
\end{abstract}

KEY WORDS: communication, competence scale, inquiry, learning science

\section{INTRODUCTION}

Science education reforms worldwide need to consider goals, curricula, resources, learning, teaching, and assessment. Success of these reforms reflects how well these facets are aligned. Taiwan's current reform outlined in the General Guidelines of Grades $1-9$ Curriculum (Taiwan Ministry of Education (MOE), 2006) points out that primary and middle schools should focus more on building a sense of competence in students rather than on memorizing facts. School curricula must be designed to ensure that students can use the skills of scientific inquiry to solve problems in the real world and then to communicate these solutions to others. However, entrance examinations for high schools and colleges in Taiwan focus exclusively on science content, which tends to cause teachers and schools to focus on learning science concepts. This dilemma stimulated the science education research community and the National 
Science Council to explore curricula and evaluation that might seek greater alignment with the MOE's goals.

A 3C-competence, cooperation, confidence-Curriculum Block Integrated Plan was developed to enhance students' science learning. The $3 \mathrm{C}$ plan involved six research projects that designed and tested curriculum and teaching approaches focused on the three attributes. These projects put equal emphasis on theory and practice to explore the potential and feasibility of various instructional approaches in a practical context of school environment to enhance students' $3 \mathrm{C}$ literacy. Five projects explored different instructional approaches: scaffolded inquiry, scientific argumentation based on digital learning, language and science learning, nature of science, and socioscientific issues. The sixth project, reported in this article, focused exclusively on assessment of the $3 \mathrm{Cs}$ in order to (a) achieve alignment among the goals, curriculum, resources, learning, teaching, and evaluation and (b) supplement existing evaluations of science knowledge. Researchers in the evaluation project developed three instruments to assess the $3 \mathrm{C}$ curriculum. This paper reports the development and results of the competence instrument.

\section{BACKGROUND}

The Organization for Economic Cooperation and Development (OECD, 2005) reported that it is quite improbable that students can acquire all the knowledge they need in schools. OECD asserts that, to better validate students' ability, they should be tested in competence in science, which would cover skills and knowledge application as well as communication ability in science rather than simply the mastery of disciplinary knowledge.

The United States' National Science Education Standards define scientific literacy as the knowledge and understanding of scientific concepts and processes (United States National Research Council (NRC), 1996). People equipped with scientific literacy would ask, seek, or decide answers to questions and can describe, explain, and predict natural phenomena as well as discuss the validity of conclusions with their peers.

Both the NRC and OECD positions on competence in science learning are reflected in Taiwan's current science education reform. Taking into account the concept of competence in science leaning, along with Taiwan's Integrated Nine-Year Nature and Science Curriculum outline, 
this study defines scientific literacy as an overall competence integrating both scientific inquiry and communication.

\section{Competence in Scientific Inquiry}

NRC (1996) advocated that students ought to develop competence in inquiry as well as in conceptual understanding. NRC (2000) asserted that students in grades $9-12$ should possess several competencies in scientific inquiry, for example, (a) identify questions, design, and conduct scientific investigations; (b) use appropriate tools and apply mathematics to gather, analyze, and interpret data; (c) formulate scientific explanations using pieces of evidence; (d) recognize and analyze alternative explanations; and (e) communicate scientific arguments.

Researchers have advocated for teachers to have students solve problems cooperatively in the context of real scenarios instead of carrying out validation experiments based solely on textbooks (Crawford, 2000). Over the years, education in Taiwan has been singularly focused on instilling knowledge in students. Eventually, students become passive receivers of knowledge and do not actively engage in learning, nor is effective learning fully achieved.

Inquiry-based learning is a strategy that encourages students to explore and gain knowledge. The United States National Science Teachers Association (NSTA) described scientific inquiry as "a powerful way of understanding science content" (NSTA, 2004, p. 1). Scientific inquiry begins with a specific problem space where scientists must develop a plan to solve the problem, formulate a hypothesis, execute an experiment, and collect evidence to interpret the problem (Selby, 2006). Likewise, students must learn how to ask questions about specific problems and answer these questions based on evidence. They learn to explore, collect pieces of evidence from different resources, construct arguments, build explanations based on available information, and communicate and defend their conclusions.

The American Association for the Advancement of Science (AAAS) asserted that "scientific inquiry [is not purely] doing experiments [or] making a great many careful observations and then organizing them" (1993, p. 9). Teachers should encourage students to undergo a cognitive process like scientists do, including present a question, form a hypothesis, design an exploration, acquire data, draw conclusions, redesign explorations, and lastly, form and revise theories. The NRC (1996) specifies that scientific inquiry refers to the diverse ways in which scientists study the natural world and propose explanations based on the evidence derived 
from their work; to students and teachers, inquiry is the activities of students in which they develop knowledge and understanding of scientific ideas, as well as an understanding of how scientists study the natural world.

Inquiry teaching and learning vary in the degree and source of structure for teacher-structured inquiries, guided inquiries, and student-directed open inquiries. In guided and open inquiries, teachers serve as facilitators and students take greater responsibility for their learning. Constructivism advocates that teachers help students think and solve problems that require higher-order thinking and rebuild their knowledge by virtue of interaction with the environment. Inquiry-based learning is an effective method to accomplish this goal.

Abell, Anderson \& Chezem (2000) contended that active pursuit of knowledge and generation of new ideas are major characteristics of an inquiry-based science class. Hinrichsen \& Jarrett (1999) pointed out four characteristics of inquiry, namely linking personal knowledge and scientific concepts, designing experiments, exploring, and constructing meaning from data and observations. They reported that most students could improve their science learning by processing their personal experiences and linking new and old knowledge. Inquiry-based learning engages students in posing questions, designing and executing exploration, analyzing, and communicating their findings in order to expand their knowledge. Jarrett (1997) suggested that inquiry learning allows students to (a) contextualize the problem within a rich environment, (b) transform these into what they could explore, (c) make assumptions, (d) plan explorations, (e) collect and analyze data, (f) draw conclusions, and finally $(\mathrm{g})$ communicate their findings with peers.

Scientific inquiry is a complex activity with multiple facets referring to activities of scientists in studying and explaining the natural world. Developing competence in scientific inquiry enables students to understand scientific knowledge and gain a systematic approach that scientists use. Since communication and discussion are important parts of learning science as well as scientific inquiry, this study separated the communication aspect for the purpose of emphasis. Therefore in this study, scientific inquiry competence is divided into four facets: presenting questions and hypothesis, planning, experimenting and data gathering, and data analyses, interpreting, and concluding.

\section{Competence in Communication}

Language is not only used to report understandings; language and the communication process shape what is known. The language arts (talking, 
listening, viewing, interpreting, reading, and writing) are essential competencies for scientists as they construct new understandings and present their research questions, experimental procedures, knowledge claims, and evidence to inform and persuade others (Yore, Florence, Pearson \& Weaver, 2006). Using discussion, argumentation, reading, and writing can help students construct understandings of science (Yore, 2009). Language is used to communicate the inquiries, procedures, and science understandings to peers so that they can assess the validity of the knowledge claims and make critical decisions about those claims. Vygotsky (1978) emphasized that learning, like doing science, is a social activity that takes place through communication or interaction with others where ideas are constructed and shared. Language helps students negotiate shared experiences, construct meaning, and report their understandings. Students new to the study of science need to discuss with their teachers and peers to understand the meaning of the world and to develop academic discourse abilities, conventions, and traditions of the scientific community. Studies reveal the importance of students' interpersonal communication with adults and peers on the improvement of their learning (Stamovlasis, Dimos \& Tsaparlis, 2005). Jenkins (1999) pointed out that scientific literacy, the central goal of many science education reforms, pertains to the ability of people to communicate with others on specific scientific issues or to collect information in daily life.

Collectively, these features support the development of interactive and constructive inquiry-based learning environments where students' understanding is the central goal. Therefore, teaching will not be effective if teachers only present facts. Instead, teachers should develop a rich discourse community and help students construct meanings through their own thinking and reasoning in an argumentative context where claims and counterclaims are made, deliberated, and supported or rebutted (NRC, 1996). Students will need to learn how to judge whether or not their peers' viewpoints and knowledge claims are correct and be able to propose counterclaims or alternative justifications. Students should be able to develop or modify an explanation based on evidence, critical thinking, and strategic reasoning instead of simply acquiring an answer. This implies that teachers need to create an environment where students can validate, criticize, and confirm their knowledge through rational dialogues (Wood, 1999).

The nature of science as inquiry and argumentation encourages students to make their deliberations, decisions about what to believe or do, and justifications for the positions and actions public and supported with evidence. They must also apply the results of experimentation to 
their arguments and build sound evidence- or theory-based explanations instead of just drawing descriptive conclusions from the inquiry. NRC (2000) suggested that students must construct the explanation from pieces of evidence after having collected them, link the explanation with established scientific knowledge, and then communicate the explanation to others.

The Programme for International Student Assessment (OECD, 2005) suggested that since inquiry is a social activity, students need the skills to communicate and establish rapport with others and the abilities to solve conflicts and work collaboratively. Campbell, Kaunda, Allie, Buffler \& Lubben (2000) pointed out that helping students develop competence in successful communication of both procedures and concepts is an indispensable part of science education and a foremost concern for science teachers. To accomplish the aim of inquiry as a collaborative, cooperative, knowledge-building activity, students must be competent communicators in both common and scientific language. This includes correct and effective expression, use of scientific and technological terms, logic and well-founded thinking, quantitative thinking, application of different methods of presentation, and use of evidence to argue, criticize, or respond (AAAS, 1993; Driver, Newton \& Osborne, 2000; Hinrichsen \& Jarrett, 1999; Jarrett, 1997).

Communication that facilitates construction of understanding, persuasion, and sharing of ideas is an essential goal of science education reforms, which promotes science literacy. Purposeful discussion in inquiry activities can enhance learning for understanding and the development of scientific discourse (Yore, Pimm \& Tuan, 2007). Language is a cognitive tool that can help construct understanding and communicate and justify ideas. Students should be able to use multiple representations to reveal concept relationships, locate and evaluate information, and construct explanations and arguments in scientific discourse (Krajcik \& Sutherland, 2010; Yore et al., 2007). Therefore, science classrooms should be communicative environments where teachers help students engage in communicating in order to facilitate effective learning (Huang, 2006).

Webb (2010) claimed that research shows that building up students' reading, writing, and talking abilities while doing science plays an important role in effective science learning. Osborne (2010) proposed that engaging students in collaborative discourse and argumentation helps enhance their conceptual understanding and reasoning capabilities. Students need opportunities to propose claims, to justify ideas they hold, and to be challenged. Through a cognitive process of comparing and 
contrasting in discourse dialogue, students can develop new understanding (Osborne) and conceptual change is most likely (van den Brock, 2010). It is important for students to have opportunities to talk, write, and represent in order to develop, explain, or argue a position in inquiry learning (Krajcik \& Sutherland, 2010). However, oral interactions and exploratory talk are underemphasized while writing-to-learn and multiple representations are being used more often in science classrooms (Yore, Bisanz \& Hand, 2003).

Contemporary science research frequently involves a team working together to explore, describe, and explain generalized patterns of events in nature (Yore et al., 2006). Yore (2009) suggested that critical features for effective language communication comprise interpersonal and intrapersonal negotiations, multimodal representations of the ideas, and transformation between representations. An inquiry-based learning environment not only puts students together but also provides a community of practice where students and teachers undertake jointly the responsibility of learning. Students are given an avenue to construct new knowledge cooperatively (Schifter, 1996). Teachers need to structure their classrooms and their instructional approaches to support dialogues; they should listen to their students and encourage them to be actively engaged. Likewise, teachers should be discerning on how to guide and facilitate discussions (Simpson, 1997).

Communication in this study is defined as a meaningful process in which the giver transforms the message into signs (oral, written, or action) and passes it to the receiver (Verderber \& Verderber, 1995). The giver codes the message into signs and passes it outwards, the receiver interprets the meaning of these signs, meaning is jointly established by the participants, and both the giver and receiver benefit from the communication act. Student understanding is clarified through communication, which strengthens the students' sense of competence in learning science. This study defines the competence of communication in learning science using four facets: expressing, evaluating, responding, and negotiating.

\section{PuRpose of the Research}

This study was conducted to develop, document, and verify the Competence Scale for Learning Science regarding competencies in scientific inquiry and communication. The development was determined by the goals of the $3 \mathrm{C}$ Curriculum Block Integrated Plan that focused on 
competence, cooperation, and confidence in learning science. The development process reported here addressed the competence goal and was based on the established literature on inquiry-based science instruction, scientific inquiry, and communications in science learning. The face validity of this instrument was established by panels of experts, teachers, and students; the structural validity was confirmed by a structural equation model; and reliability was established using internal consistency. Specifically, the verification part of this study investigated:

1. What is the level of consistency and stability of the Competence Scale in measuring the competence of students in learning science?

2. What is the validity of the Competence Scale on the measurement of the competence of students in learning science?

\section{Methodology}

Competence in learning science, as defined in this study, encompasses the competencies of scientific inquiry and of communication. Scientific inquiry refers to solving a problem by establishing evidence and logical analysis while acquiring scientific knowledge. Communication pertains to messages that could be transferred clearly and can be confirmed as correctly received after validation. Scientific inquiry uses diverse symbolic representations (e.g. mathematical signs, graphs, and tables) that influence both science learning and reporting what was learned. The competence of using these symbolic representations to express meaning and negotiate with peers, or respond to and evaluate others' notions, is the basis for communication in learning science.

\section{Facets of Competence in Scientific Inquiry}

This study attempts to illustrate and document the four facets of scientific inquiry as described in the following:

1. Presenting questions and hypothesis - students pose a question or hypothesis based on experience, evidence, or theory in learning science.

2. Planning - students adopt a suitable strategy for specific questions or hypotheses, employ resources, and then work out a problem-solving approach. 
3. Experimenting and data gathering - students gather data with a suitable tool as planned.

4. Data analyzing, interpreting, and concluding - students analyze data and establish evidence, build the link between evidence and conclusion, and then establish the relationship between evidence and conclusion to form a model or explanation through logical thinking.

\section{Facets of Competence in Communication}

This study attempts to illustrate and document the four facets of communication in learning science as described in the following:

1. Expressing - students use verbal and written language, mathematical signs, graphs, and other representations to pass on messages appropriately.

2. Evaluating - students analyze or judge the rationality of their or others' arguments.

3. Responding - students adopt suitable actions based on their peers' messages.

4. Negotiating — students reach an agreement with peers through discussion.

\section{Scale Development Process}

This scale includes two constructs with four facets in each construct. The researchers examined the literature, international reform standards, and national curriculum outcomes to better define the structures and expected competencies regarding scientific inquiry and communication. Fourteen indices for scientific inquiry and 12 indices for communication were identified ("Appendix 1"). Researchers developed two to three items for each index and built a pool of 81 Likert-type items consisting of a focus statement and a five-option response scale. There were seven to ten items in each of the four facets of the two constructs.

Researchers invited three local scholars in the field of science education and measurement to examine the appropriateness of each item. The criteria for this review were conformity between the indices and the item description and the item's implication and suitability for learning science in primary, middle, and high schools. The scholars were also requested to recommend revisions that would strengthen the utility of the item descriptions. Items that were judged as invalid measures of the construct were deleted, and items that were either ambiguous or otherwise unclear were revised. As a result, the preliminary Competence in 
Scientific Inquiry subscale consisted of 38 items, and the preliminary Competence in Communication subscale consisted of 30 items.

The wording of the 68 items was explored to ensure appropriateness for the target grade levels. Experienced teachers and students were asked to review the appropriateness of the items' expression. The items were modified based on the feedback from this review to ensure students could read and understand the content.

\section{Verification Process}

Verification of the preliminary competence scale and subscales consisted of establishing item difficulty and discrimination, face and structural validity, and reliability. This investigation used a large-group trial and analysis of the resulting data.

Trial Groups of Students. Three trial groups of students were selected from primary, junior, and senior high schools in northern, central, and southern Taiwan. A convenience sample of 1,812 students was recruited for the initial instrument trial in order to conduct an item analysis and select items for the final instrument; complete responses were received from 1,697 students. Another 847 students out of a convenience sample of 907 were used for the second trial in order to refine the item selection. The third group of 1,602 students was selected using a proportional random sampling method from the three regions, three school levels, and genders for the reliability and validity analyses. Complete responses were provided by 1,392 students, of which 407 students were selected for reliability and validity analysis.

Analysis of the Data. The results from the trial study were analyzed using SPSS 12.0 for Windows. In the first stage, items were evaluated based on the item analysis results. Items meeting any of following criteria were deleted:

- The mean of the item is higher or lower than the mean score of all items by 1 standard deviation (SD), its SD is less than 0.60 , and its skewness coefficient approaches +1 or -1

- According to scale score, the top and bottom 1/3 of the students were chosen as the high- and low-score groups, respectively, and $t$ test was carried out on the mean scores of these two groups. Items with a nonsignificant difference $(\alpha=0.05)$ between the high-score group and low-score group were considered to have low discrimination power 
- The correlation coefficient between an item and the total score is less than 0.30

- The internal consistency (Cronbach $\alpha$ ) of whole scale was higher after deleting an item

The items retained in the two constructs were then subjected to factor analysis based on the predefined facets. Those items with low factor loadings on the anticipated factors were deleted, resulting in retention of 33 and 22 items for the Scientific Inquiry and Communication subscales, respectively.

However, experts on the $3 \mathrm{C}$ team suggested that 55 items were too many and may exhaust the respondents. A second trial was conducted to determine if other items could be deleted without reducing the reliability or validity of the instrument. Items were analyzed by the same procedure used in the first trial, resulting in 14 and 15 items retained for the Scientific Inquiry and Communication subscales, respectively, for the final version of the Competence Scale.

The third trial focused on verification of the final version of the Competence Scale. Cronbach $\alpha$ analysis was employed to analyze internal consistency within the final subscales, the combined scales, and the full scale. Confirmatory factor analysis with structural equation modeling was employed to analyze the conformity between empirical data and theoretical structure. These were validated based on three indices: preliminary fit criteria, overall model fit, and fit of internal structure (Bagozzi \& Yi, 1988). Preliminary fit criteria are employed to examine the appropriateness of estimated parameters in the model. Overall model fit is used to examine the fit between the theoretical and the empirical model (Hair, Anderson, Tatham \& Black, 1998). After the overall model fit is examined and the conformity of the theoretical model to the empirical data is ensured, the appropriateness of observed indices is assessed to understand the model's internal quality.

\section{Results AND Discussion}

The results and discussions are organized to reflect the research questions. Reliability was considered first and validity was considered second.

\section{Scale Structure}

Based on relevant theory and the results of this study, competence in learning science is divided into two constructs: Competence in Scientific 
Inquiry and Competence in Communication. The two combined scales and the four subscales are described as follows:

1. The combined scale of Competence in Scientific Inquiry consists of four subscales: presenting questions and hypothesis, planning, experimenting and data gathering, and data analyzing, interpreting, and concluding.

2. The combined scale of Competence in Communication consists of four subscales: expressing, evaluating, responding, and negotiating.

The Competence Scale has a total of 29 items; 14 items are in the Scientific Inquiry combined scale, 15 items are in the Communication combined scale, and three or four items are in each subscale ("Appendix 2"). The scales consist of self-report, five-point Likert-type items in which respondents select the most suitable answer. This scale has only positive-score questions: $1=$ never, $2=$ seldom, $3=$ sometimes, $4=$ often, and $5=$ always. The total scores are the sum of the scores of all items in the total scale. A higher score indicates higher overall competence. This instrument was designed to be administered individually or in groups, with or without time constraints. Usually, respondents completed all questions within $20 \mathrm{~min}$.

\section{Reliability and Validity of the Scale}

The homogeneity and reliability of the scale was evaluated, and results are reported in Table 1. The Cronbach $\alpha$ is 0.95 for the full scale and $0.71-0.92$ for the combined scales and subscales. These results reflect high to reasonable internal consistencies for the full scale, the two combined scales, and the eight subscales (van Ornum, Dunlap \& Shore, 2008).

Figure 1 presents the structural equation model of the Competence Scale while Table 2 presents the results of the confirmatory factor analysis. As can be seen from Figure 1, the correlations among factors are from 0.55 to 0.94 and the factor loadings are from 0.64 to 0.79 . Table 2 indicates that the error variation in the model's estimated parameters of preliminary fit criteria are all positive, reaching a 0.05 level of significance. The correlation coefficient between the estimated parameters is between -0.665 and 0.759 . The factor loadings are between 0.641 and 0.795 while the standard error of estimate is between 0.070 and 0.084 . Based on these results, it is appropriate to conclude that the estimated parameters in the theoretical model of the scale conform to basic requirements of model fit. The conformity between theoretical model and empirical data justifies further examination of fit criteria.

First, the total fit criteria indicate that the results are significant $(p<0.05)$, which means that the theoretical model is not equivalent to the empirical 
TABLE 1

Internal consistency reliability of 3CLB-competence scale

\begin{tabular}{lc}
\hline Subscale & Cronbach $\alpha$ coefficient \\
\hline Scientific Inquiry combined scale & 0.90 \\
Presenting questions and hypothesis & 0.71 \\
Planning & 0.79 \\
Experimenting and data gathering & 0.76 \\
Data analyzing, interpreting, and concluding & 0.80 \\
Communication combined scale & 0.92 \\
Expressing & 0.81 \\
Evaluating & 0.81 \\
Responding & 0.75 \\
Negotiating & 0.80 \\
Full scale & 0.95 \\
\hline
\end{tabular}

model. However, examination of the other indices reveal that the ratio between $\chi^{2}$ and degree of freedom is lower than the prescribed criterion of 5, the root mean square residual is less than 0.05 , the root mean square error of approximation is less than 0.08 , and both goodness of fit index and adjusted goodness of fit index are close to 0.90 . These values are consistent with or equivalent to the criteria, indicating absolute fit of the overall model, which means that the two models are consistent. Second, consideration of incremental fit criteria revealed that the Bentler-Bonett normed fit index and Bollen's relative fit index are close to the criteria of 0.90 while the Bollen's incremental fit index, Tucker-Lewis index, and comparative fit index exceed the criteria of 0.90 . These results indicate good incremental fit of the overall model. Third, consideration of the Akaike information criterion values of the theoretical model revealed smaller values than the independent and saturated models. However, the parsimonious goodness of fit index, parsimonious normed fit index, and parsimonious comparative fit index indices resulted in $0.704,0.705$, and 0.791 values, respectively, which exceed the criteria of 0.50 . In addition, the consistent Akaike information criterion values of the theoretical model are smaller than the independent and saturated models. Therefore, the overall model is considered to be parsimonious, and the three indices of total fit indicate that empirical data support this theoretical model.

Finally, the internal fit criteria of the model were analyzed to understand the internal quality when the overall theoretical model fits the model of empirical data. Table 2 indicates that the $t$ value of estimated parameters is between 6.952 and 14.000, reaching the 0.05 level of significance. Squared multiple correlation (SMC) of observed variables is between 0.411 and 


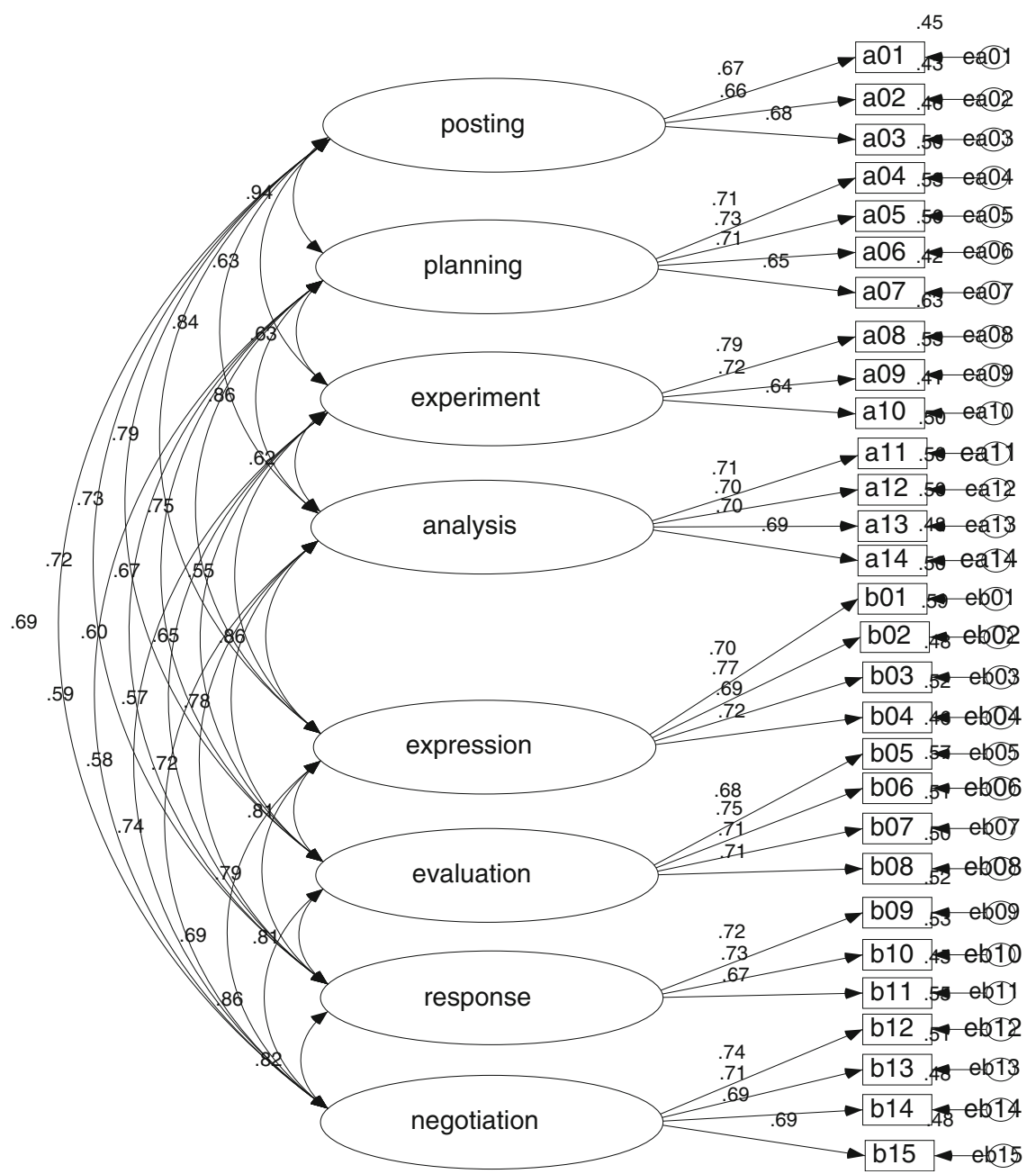

Figure 1. Model of competence scale and results of confirmatory factor analysis

0.632. SMC of 15 items (a01, a02, a03, a06, a07, a10, a12, a13, a14 and b01, $\mathrm{b} 03, \mathrm{~b} 05, \mathrm{~b} 11, \mathrm{~b} 14, \mathrm{~b} 15)$ approaches 0.50 , indicating that these items could be explained by the corresponding factors. Average variance extracted of latent variables is between 0.45 and 0.82 . Three latent variables (i.e. presenting questions and hypothesis, planning, and data analyzing, interpreting, and concluding) are less than 0.50 but still within the acceptable range (Arbuckle \& Wothke, 1999), which shows that latent variables can interpret observed items adequately. Composite reliability of latent variables is between 0.71 and 0.81 and greater than the criterion of 0.60 , which means that the items have high correlation within each subscale. 
TABLE 2

Results of confirmatory factor analysis of 3CLB-competence scale $(N=407)$

\begin{tabular}{|c|c|c|}
\hline Criterion & Result & Judgment \\
\hline \multicolumn{3}{|l|}{ Preliminary fit standard } \\
\hline No negative error variance & All positive & Conforms \\
\hline $\begin{array}{l}\text { All error variance reaches the level } \\
\text { of significance* }\end{array}$ & All were significant* & Conforms \\
\hline $\begin{array}{l}\text { Correlation between estimated parameters } \\
\text { is not close to }+1 \text { or }-1\end{array}$ & $-0.665-0.702$ & Conforms \\
\hline Factor loading is between 0.50 and 0.95 & $0.641-0.795$ & Conforms \\
\hline No big standard error & $0.070-0.084$ & Conforms \\
\hline \multicolumn{3}{|l|}{ Overall model fit } \\
\hline \multicolumn{3}{|l|}{ 1. Absolute fit criteria } \\
\hline$\chi^{2}$ does not reach the level of significance* & $793.274 *$ & $\begin{array}{l}\text { Fails to } \\
\text { conform }\end{array}$ \\
\hline$\chi^{2} / d f$ is $<5$ & 2.273 & Conforms \\
\hline $\mathrm{RMR}<0.05$ & 0.048 & Conforms \\
\hline $\begin{array}{l}\text { RMSEA }<0.08 \text { (excellent if }<0.05 \\
\text { good if }<0.08 \text { ) }\end{array}$ & 0.056 & Conforms \\
\hline GFI $>0.90$ & 0.878 , close to 0.90 & Acceptable \\
\hline AGFI $>0.90$ & 0.848, close to 0.90 & Acceptable \\
\hline \multicolumn{3}{|l|}{ 2. Incremental fit criteria } \\
\hline $\mathrm{NFI}>0.90$ & 0.867 , close to 0.90 & Acceptable \\
\hline RFI $>0.90$ & 0.845 , close to 0.90 & Acceptable \\
\hline IFI $>0.90$ & 0.921 & Conforms \\
\hline TLI $>0.90$ & 0.907 & Conforms \\
\hline CFI $>0.90$ & 0.920 & Conforms \\
\hline \multicolumn{3}{|l|}{ 3. Parsimonious fit criteria } \\
\hline PGFI $>0.50$ & 0.704 & Conforms \\
\hline PNFI $>0.50$ & 0.745 & Conforms \\
\hline PCFI $>0.50$ & 0.791 & Conforms \\
\hline AIC: TMV is less than SMV and IMV & $\begin{array}{l}965.274(\mathrm{TMV})>870.000(\mathrm{SMV}) \\
965.274(\mathrm{TMV})<6,024.242 \text { (IMV) }\end{array}$ & $\begin{array}{l}\text { Fails to } \\
\text { conform }\end{array}$ \\
\hline $\begin{array}{l}\text { CAIC: TMV is less than the SMV } \\
\text { and IMV }\end{array}$ & $\begin{array}{r}1,396.032(\mathrm{TMV})<3,048.834(\mathrm{SMV}) \\
1,396.032(\mathrm{TMV})<6,169.497(\mathrm{IMV})\end{array}$ & Conforms \\
\hline \multicolumn{3}{|l|}{ Internal fit } \\
\hline $\begin{array}{l}\text { Estimated parameters reach level of } \\
\text { significance* }\end{array}$ & $t$ is between 6.952 and 14.000 & Conforms \\
\hline SMC of individual items is greater than 0.50 & SMC is between 0.41 and 0.63 & Acceptable \\
\hline $\begin{array}{l}\text { Average variance extracted of latent } \\
\text { variables is greater than } 0.50\end{array}$ & Between 0.45 and 0.82 & Acceptable \\
\hline $\begin{array}{l}\text { Composite reliability of latent variables } \\
\text { is greater than } 0.60\end{array}$ & Between 0.71 and 0.81 & Conforms \\
\hline
\end{tabular}

RMR root mean square residual, RMSEA root mean square error of approximation, GFI goodness of fit index, $A G F I$ adjusted goodness of fit index, $N F I$ normed fit index, $R F I$ relative fit index, $I F I$ incremental fit index, $T L I$ Tucker-Lewis index, $C F I$ comparative fit index, $P G F I$ parsimonious goodness of fit index, $P N F I$ parsimonious normative fit index, $P C F I$ parsimonious comparative fit index, AIC Akaike information criterion, $T M V$ theoretical model value, $S M V$ saturated model value, $I M V$ independent model value, $C A I C$ consistent Akaike information criterion, $S M C$ squared multiple correlation $* p<0.05$ 
The model criteria indicate that the estimated parameters in the scale model do not violate the model's basic requirements as a whole. In addition, it was determined that this theoretical model could be supported by the empirical data and has an acceptable absolute fit, good incremental fit, and ideal parsimony. As demonstrated by the indices applied in the theoretical model (preliminary fit, overall model fit, and fit of internal structure criteria), the theoretical model of Competence in Learning Science fits well. Results of the confirmatory factor analysis indicate that the scale and subscales are valid and the theoretical structural relationship between items and subscales were supported by empirical data.

\section{Conclusion And Suggestions}

The purpose of this study was to develop a Competence Scale for high, middle, and primary school students in Taiwan. The survey was a tool used by students to self-report and is comprised of two scales: Competence in Scientific Inquiry and Competence in Communication.

The verification results for the Competence Scale demonstrate reasonable internal consistency, acceptable validity, and strong internal isomorphism. These factors indicate that it is valid and reliable measuring tool. Therefore, it can be considered a good measuring tool that can be used for either teaching or study purposes. Researchers and science teachers of $3 \mathrm{C}$ curricula utilized this instrument to gauge students' competence in learning science and to understand their competencies in diverse situations as well as to rectify any unsatisfactory situations. In academic studies, this instrument could be used as a tool to measure the effects of experimental courses in science education and to interpret the feasibility of experimental plans.

In addition to science concept learning, building students' competence to learn actively is an important goal of science education. Although qualitative assessments are often implemented, it is time-consuming and teachers need prior practical training. This Competence Scale offers teachers a convenient way to assess students' competence.

In order to increase the instrument's practicality in actual teaching, it is suggested to develop norm and provide reference to test results. Through the Competence Scale, teachers or examinees could understand students' relative status in competence in learning science.

\section{ACKNOWLEDGMENTS}

This study was supported by the Taiwan National Science Council. We are grateful to anonymous reviewers for reviewing earlier versions of this 
manuscript. We deeply appreciate the English mentoring service provided by IJSME. We also appreciate the help from Dr. Yore and Mrs. Yore; the final version would not have been possible without their constructive comments.

Open Access This article is distributed under the terms of the Creative Commons Attribution Noncommercial License which permits any noncommercial use, distribution, and reproduction in any medium, provided the original author(s) and source are credited.

\section{Appendix 1: Indices of Competency Scale}

Scientific Inquiry subscale

1. Presenting questions and hypothesis

2. Planning

3. Experiment and data gathering

4. Data analyzing, interpretation, and concluding

Communication subscale
Be able to pose question according to data observed

Be able to pose an explorable question

Be able to describe concept with operational definition

Be able to pose verifiable hypothesis according to data

Be able to pose feasible explorative plan according to question

$\mathrm{Be}$ able to manipulate variables related to plan

Be able to control extraneous variables that may interfere

with results

Be able to experiment according to predefined plan

Be able to collect data through different methods

Be able to record data through different instruments

Be able to compare and classify data collected from experiment

Be able to describe and interpret data through scientific terminology

Be able to build conclusion according to collected data

Be able to infer according to collected data
1. Expressing
2. Evaluating

3. Responding

4. Negotiating
Be able to describe data through multiple representations

Be able to describe relationship among data

Be able to comprehend meaning of data presented by different representations

Be able to view message through different ways or aspects

Be able to justify the correctness of data or argument

Be able to differentiate facts and inference

Be able to clarify ambiguous messages

Be able to ascertain messages from peers

Be able to respond messages from peers

Be able to differentiate difference between ideas of oneself and peers

Be able to revise own idea according to peers' opinions

Be able to reach a common consensus through discussion with peers 


\section{Appendix 2: Competence Scale}

Subscale Item

\begin{tabular}{l} 
Scientific Inquiry scale \\
\hline Presenting questions and hypothesis a01. In science class, I could ask questions about what \\
I don't understand through observation. \\
a02. When learning science, I could collect information \\
related with questions to obtain deeper understanding. \\
a03. When learning science, I could deduce possible answers \\
to the questions. \\
a04. In science class, I could describe what data should be \\
collected in the experiment. \\
a05. In science class, I could choose suitable study methods \\
based on the question. \\
a06. In science class, I could consider possible factors that \\
may influence the experiment. \\
a07. In science class, I could design the experimental steps \\
based on the question. \\
a08. In science class, I could observe and record results of \\
the experiment carefully. \\
a09. In science class, I could operate the experimental \\
apparatus to measure data. \\
a10. In science class, I could carry out the experiment in \\
accordance with the experiment's procedures. \\
a11. In science class, I could compare or classify data \\
collected in the experiment. \\
a12. In science class, I could use scientific terms learned to \\
explain the meaning of experimental data. \\
a13. In science class, I could draw conclusions based on the \\
mathematical relationship among experimental data. \\
a14. In science class, I could explain experimental results or \\
phenomena based on the experiment's conclusion. \\
Data analyzing, interpreting, and ancluding
\end{tabular}

Communication scale

b01. In science class, I could use graphs or mathematical signs to describe the data content.

b02. In science class, I could convert raw data into a readily understandable form and present it.

b03. In science class, I could describe data relationships verbally or in writing.

b04. In science class, I could describe data relationships through graphs or mathematical signs.

Evaluating b05. In science class, I could think about the question from another perspective.

b06. In science class, I could analyze whether my expression is consistent with what I want to express.

b07. In science class, I could judge whether others' statements (verbal or written) are correct based on the knowledge learned.

b08. In science class, I could discriminate between facts and deduction. 
Responding

Negotiating b09. In science class, I could ask questions about ambiguous statements from peers.

b10. In science class, I could ask peers who do not describe clearly to explain again.

b11. In science class, I could explain my viewpoint with different methods when peers do not understand my point.

b12. In science class, I could find the differences and similarities between different opinions through discussion.

b13. In science class, I could examine whether my thoughts contradict themselves based on peers' advice.

b14. In science class, I could correct my wrong idea based on peers' correct opinion.

b15. In science class, I could share opinions with peers through discussion.

\section{REFERENCES}

Abell, S. K., Anderson, G. \& Chezem, J. (2000). Science as argument and explanation: Exploring concepts of sound in third grade. In J. Minstrell \& E. H. van Zee (Eds.), Inquiring into inquiry learning and teaching in science (pp. 65-79). Washington, DC: American Association for the Advancement of Science.

American Association for the Advancement of Science (1993). Benchmarks for science literacy: Project 2061. New York: Oxford University Press.

Arbuckle, J. L. \& Wothke, W. (1999). Amos 4.0 user guide. Chicago: SmallWaters Corporation.

Bagozzi, R. P. \& Yi, Y. (1988). On the evaluation of structural equation models. Journal of the Academy Marketing Science, 16(1), 74-94.

Campbell, B., Kaunda, L., Allie, S., Buffler, A. \& Lubben, F. (2000). The communication of laboratory investigations by university entrants. Journal of Research in Science Teaching., 37(8), 839-853.

Crawford, B. A. (2000). Embracing the essence of inquiry: New roles for science teachers. Journal of Research in Science Teaching, 37(9), 916-937.

Driver, R., Newton, P. \& Osborne, J. (2000). Establishing the norms of scientific argumentation in classrooms. Science \& Education, 84(3), 287-312.

Hair, J. F., Jr., Anderson, R. E., Tatham, R. L. \& Black, W. C. (1998). Multivariate data analysis (5th ed.). Upper Saddle River, NJ: Prentice Hall.

Hinrichsen, J. \& Jarrett, D. (1999). Science inquiry for the classroom. Portland, OR: Northwest Regional Educational Laboratory.

Huang, H. J. (2006). Listening to the language of constructing knowledge. International Journal of Science and Math Education, 4(3), 391-415.

Jarrett, D. (1997). Inquiry strategies for science and mathematics learning. Portland, OR: Northwest Regional Educational Laboratory.

Jenkins, E. W. (1999). School science, citizenship and the public understanding of science. International Journal of Science Education, 21(7), 703-710.

Krajcik, J. S. \& Sutherland, L. M. (2010). Supporting students in developing literacy in science. Science, 328(5987), 456-459. 
National Science Teachers Association (2004). NSTA position statement: Scientific inquiry. Arlington, VA: Author.

Organization for Economic Cooperation and Development (2005). The definition and selection of key competencies: Executive summary. Paris, France: Author.

Osborne, J. (2010). Arguing to learn in science: The role of collaborative, critical discourse [Special Issue]. Science, 328(5977), 463-466.

Schifter, D. (1996). What's happening in math class? Envisioning new practices through teacher narratives (Vol. 1). New York: Teachers College Press.

Selby, C. C. (2006). What makes it science?: A modern look at scientific inquiry. Journal of College Science Teaching, 35(7), 8-11.

Simpson, D. (1997). Collaborative conversations. Science Teacher, 64(7), 40-43.

Stamovlasis, D., Dimos, A. \& Tsaparlis, G. (2005). A study of group interaction processes in learning lower secondary physics. Journal of Research in Science Teaching, 43(6), $556-576$.

Taiwan Ministry of Education (2006). Grade 1-9 curriculum of junior high and primary school: Science and technology. Taipei, Taiwan: Author.

United States National Research Council (1996). The national science education standards. Washington, DC: The National Academies Press.

United States National Research Council (2000). Inquiry and the national science education standards: A guide for teaching and learning. Washington, DC: The National Academies Press.

van den Brock, P. (2010). Using texts in science education: Cognitive processes and knowledge representation. Science, 328(5977), 453-456.

van Ornum, B., Dunlap, L. L. \& Shore, M. F. (2008). Psychological testing across the lifespan. Upper Saddle River, NJ: Pearson Education.

Verderber, R. F. \& Verderber, K. S. (1995). Inter-ACT: Using interpersonal communication skills. Belmont, CA: Wadsworth.

Vygotsky, L. S. (1978). Mind in society: The development of higher psychological processes. Cambridge, MA: Harvard University Press.

Webb, P. (2010). Science education and literacy: Imperatives for the developed and developing world [Special Issue]. Science, 328(5977), 448-450.

Wood, T. (1999). Creating a context for argument in mathematics. Journal for Research in Mathematics Education, 30(2), 171-191.

Yore, L. D. (2009). Science literacy for all-more than a logo or rally flag! Proceedings of International Science Education Conference 2009 (pp. 2393-2427). Singapore, Singapore: National Institute of Education.

Yore, L. D., Bisanz, G. L. \& Hand, B. (2003). Examining the literacy component of science literacy: 25 years of language arts and science research. International Journal of Science Education, 25(6), 689-725.

Yore, L. D., Florence, M. K., Pearson, T. W. \& Weaver, A. J. (2006). Written discourse in scientific communities: A conversation with two scientists about their views of science, use of language, role of writing in doing science, and compatibility between their epistemic views and language. International Journal of Science Education, 28(2/3), 109-141. 
Yore, L. D., Pimm, D. \& Tuan, H. L. (2007). The literacy component of mathematical and scientific literacy [Special Issue]. International Journal of Science and Math Education, 5(4), 559-589.

Huey-Por Chang and Chin-Chang Chen

Department of Physics

National Changhua University of Education

Changhua, Taiwan

E-mail: ccchen@cc.ncue.edu.tw

Huey-Por Chang

E-mail: Changhp@cc.ncue.edu.tw

Gwo-Jen Guo

Department of Guidance and Counseling

National Changhua University of Education

Changhua, Taiwan

E-mail: Gerald@cc.ncue.edu.tw

Yeong-Jin Cheng

Department of Life Science

National Taiwan Normal University

Taipei, Taiwan

E-mail:yjcheng@ntnu.edu.tw

Chen-Yung Lin

Graduate Institute of Science Education

National Taiwan Normal University

Taipei, Taiwan

E-mail:lcy@ntnu.edu.tw

Tsung-Hau Jen

Center of Science Education

National Taiwan Normal University

Taipei, Taiwan

E-mail: tsunghua@ntnu.edu.tw 